\section{Trunk Renewal Methods for Recovery of 'Cabernet franc' Grapevines after Winter Injury in Ohio}

\author{
Thomas M. Todaro ${ }^{1}$ and Imed E. Dami ${ }^{2,3}$
}

AdDITIONAL INDEX wORDs. Cane pruning, cropload, fan system, freeze damage, fruit composition, leaf area, vine balance

Summary. 'Cabernet franc' grapevines (Vitis vinifera) sustained severe winter injuries of all aboveground parts following two consecutive freezing events in 2014 and 2015 in Ohio. To ensure grapevine recovery, adjustment of pruning and training practices must be accomplished. However, optimum training of new shoots for trunk replacement was not known and research-based information on this topic was lacking. Therefore, the purpose of this study was to evaluate different training and pruning methods for trunk renewal and recovery of 'Cabernet franc' and their impacts on growth, yield, cropload, and fruit composition following severe winter injuries. In 2016, grapevines were manipulated using a combination of training [Fan, vertical shoot positioning (VSP), or both], pruning (cane- or spur-pruned), and trunks (two, four, or more trunks per vine). The Fan system took less time to train than VSP during the growing season; however, the latter took less time to train and prune during the following dormant season. Training and pruning methods with increased buds per vine resulted in increased shoots, leaf area, pruning weight, clusters, and yield per vine but decreased juice total soluble solids (TSS). The exceptions were vines with combined training systems of Fan and VSP, in which leaf areas and pruning weights were reduced despite increased bud count per vine after pruning. In conclusion, each system has advantages and disadvantages; however, the Fan training system with cane pruning and multiple trunks produced the most optimum trunk size, yield, cropload, and fruit composition. Therefore, following trunk freeze injury, we recommend retaining all shoots using the Fan training during the growing season. During the subsequent dormant season, growers should select medium-sized canes for trunk replacement and train four trunks and four canes for the VSP system.

$\mathrm{F}$ reezing is the leading environmental stress that causes crop loss to the grape industry in Ohio and surrounding states (Zabadal et al., 2007). From 2007 through 2015, Ohio grape growers experienced consecutive freezing events with unprecedented crop and vine losses valued at \$12 million following

The paper is a portion of a thesis submitted by Thomas Todaro in fulfilling an MS degree requirement. This research was supported by funding from the Department of Horticulture and Crop Science, NIFA Specialty Crops Research Initiative Award Number 2010-51181-21599, and Ohio Grape Industries Program. We thank Nick Ferrante for his collaboration on this project by permitting us to use his vineyard. Mention of a trademark, proprietary product, or vendor does not constitute a guarantee or warranty of the product by the U.S. Department of Agriculture and does not imply its approval to the exclusion of other products or vendors that may also be suitable.

${ }^{1}$ Agriculture and Agribusiness Institute, Michigan State University, 8527 E. Government Center Drive, Ste 107, Suttons Bay, MI 49682

${ }^{2}$ Department of Horticulture and Crop Science, Ohio Agricultural Research and Development Center, The Ohio State University, 1680 Madison Avenue, Wooster, $\mathrm{OH} 44691$

${ }^{3}$ Corresponding author. E-mail: dami.1@osu.edu.

https://doi.org/10.21273/HORTTECH03997-18 the "polar vortex" event in 2014 (Dami and Lewis, 2014). Multiple freezing events of air temperatures below $-20{ }^{\circ} \mathrm{C}$ occurred in Jan. and Feb. 2014. These extreme and repeated freezing events damaged trunks, canes, and buds and resulted in $88 \%$ to $100 \%$ crop loss to all vinifera (Vitis vinifera) cultivars throughout the state (Dami et al., 2014). In 2014, only buds at the base of trunks that had been buried under soil mounds survived. The practice of soil hilling (covering the graft union and trunk base with soil) is a worst case scenario measure when grapevine dieback occurs and intends to protect buds at the base of the scion for trunk renewal during the following season (Howell, 1988; Zabadal et al., 2007). In this situation, vine recovery was accomplished by retraining new shoots for trunk replacement. To restore growth balance, grapevines are managed differently by training multiple shoots (called suckers) from the trunk base on a fan-like shape, thus the name, Fan training system (Wolfe, 2000; Zabadal et al., 2007). However, in 2015, the multiple 1-year-old canes, trained as new trunks, were again exposed to multiple freezing events in January and February of air temperature below $-20{ }^{\circ} \mathrm{C}$ (Fig. 1). As a result, all 1-year-old canes were killed except for the buried portion of the canes, which were protected by soil hilling.

To mitigate freezing damage in grapevines, various protection methods have been developed and implemented before, during, or after a freezing event, with the purpose of enhancing grapevine recovery (Poling, 2008; Zabadal et al., 2007). Following winter injury, vine recovery management strategy is a key cultural practice that involves adjustment of pruning and training with the goal to reestablish vine structure and resume predamage crop production (Howell, 1988; Pool and Howard, 1985). However, growers have relied on anecdotal information because of lack of published research on vine retraining options. Even though these back-to-back damaging events were devastating for growers, they presented an opportunity to conduct a field study to address the issue of optimum training methods for trunk renewal and thus provide research-based guidelines on

\begin{tabular}{llll}
\hline $\begin{array}{l}\text { Units } \\
\begin{array}{l}\text { To convert U.S. to SI, } \\
\text { multiply by }\end{array}\end{array}$ & U.S. unit & SI unit & $\begin{array}{l}\text { To convert SI to U.S., } \\
\text { multiply by }\end{array}$ \\
\hline 29.5735 & $\mathrm{fl} \mathrm{oz}$ & $\mathrm{mL}$ & 0.0338 \\
0.3048 & $\mathrm{ft}$ & $\mathrm{m}$ & 3.2808 \\
0.0929 & $\mathrm{ft}^{2}$ & $\mathrm{~m}^{2}$ & 10.7639 \\
0.2048 & $\mathrm{ft}^{2} / \mathrm{lb}$ & $\mathrm{m}^{2} \cdot \mathrm{kg}^{-1}$ & 4.8824 \\
2.54 & inch $(\mathrm{es})$ & $\mathrm{cm}$ & 0.3937 \\
25.4 & inch $(\mathrm{es})$ & $\mathrm{mm}$ & 0.0394 \\
0.4536 & $\mathrm{lb}$ & $\mathrm{kg}$ & 2.2046 \\
1.4882 & $\mathrm{lb} / \mathrm{ft}$ & $\mathrm{kg} \cdot \mathrm{m}^{-1}$ & 0.6720 \\
0.001 & $\mathrm{ppm}$ & $\mathrm{g} \cdot \mathrm{L}^{-1}$ & 1,000 \\
$\left({ }^{\circ} \mathrm{F}-32\right) \div 1.8$ & $\mathrm{o} F$ & ${ }^{\circ} \mathrm{C}$ & $\left({ }^{\circ} \mathrm{C} \times 1.8\right)+32$ \\
& & &
\end{tabular}




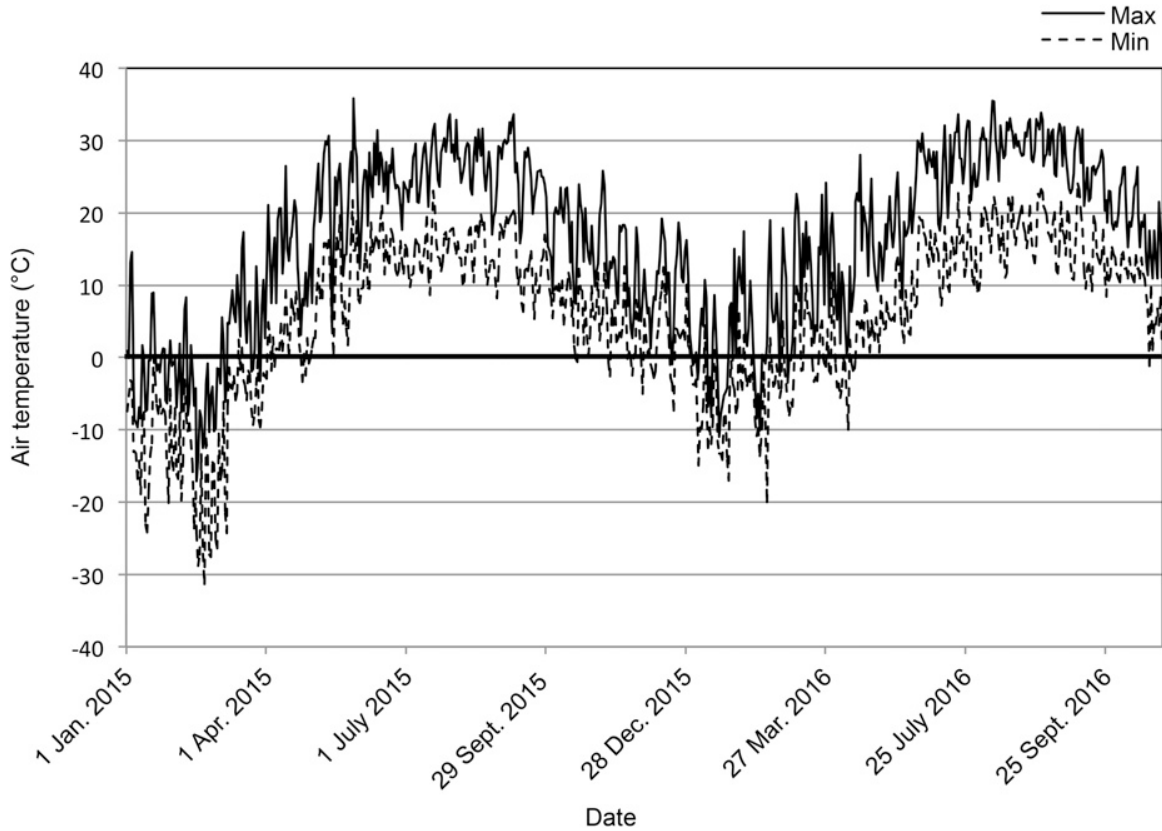

Fig. 1. Hourly maximum (solid line) and minimum (dashed line) air temperatures recorded from 1 Jan. 2015 to 31 Oct. 2016 using a temperature data logger located in the vineyard in Geneva, $\mathrm{OH}\left(1.8 \times{ }^{\circ} \mathrm{C}\right)+32={ }^{\circ} \mathrm{F}$.

cultural practices for grapevine recovery. Therefore, the purpose of this study was to evaluate different training and pruning methods for trunk renewal and recovery of 'Cabernet franc' and their impacts on growth, yield, cropload, and fruit composition following severe winter injuries.

\section{Materials and methods \\ Plant material, experimental design, and treatments}

This research study started in Spring 2015 and was conducted at a commercial vineyard in Geneva (lat. $41.7627^{\circ} \mathrm{N}$, long. $80.9629^{\circ} \mathrm{W}$, altitude $257 \mathrm{~m}$; soil series, Platea-Darien silt loams) in northeast Ohio [USDA Plant Hardiness Zone 6a $(-23.3$ to $-20.6{ }^{\circ} \mathrm{C}$ ) (U.S. Department of Agriculture, 2012)]. Five-year-old 'Cabernet franc' grafted onto rootstock '101-14' (Vitis riparia $\times$ Vitis rupestris), planted in 2010 in a northsouth orientation with a spacing of $4 \times 9 \mathrm{ft}$ (vine $\times$ row), were used in this study. Before winter damage, grapevines were originally head-trained and cane-pruned with two canes ( 12 buds per cane and totaling 24 buds per vine), tied horizontally to the fruit wire, and were vertically shootpositioned. In Spring 2015, all damaged trunks were removed before treatment application. The shoots used in this study were suckers that emerged from the scion portion of the trunk that was buried and originated mainly from count buds on 1 -year-old spurs and noncount buds off the trunk (Fig. 2D). Three training systems were applied to 15 vines per treatment in a randomized complete block design with four blocks. Treatments were Fan, Fan/VSP, and VSP training systems (Fig. 2). On Fantrained vines, all emerged shoots were manually trained vertically by tucking and positioning them between catch wires into a fan shape (Fig. 2A-D). All shoots and fruit (clusters) were retained in this system. Fan/VSP training involved training four shoots on a VSP system and the remaining shoots on Fan system (Fig. 2E-H). All shoots were retained and clusters were removed from the VSP-trained shoots only. In VSP training, four shoots were retained and trained vertically, and then two shoots were trained horizontally in opposite direction along the fruit wire (Fig. 2I-L). The remaining shoots and all fruit were removed. Throughout the study, grapevines were maintained using standard commercial practices (Dami et al., 2005). During the fall and after harvest, soil hilling was conducted using a disc plow (Maxiumus 100; Unverferth Manufacturing Co., Kalida, $\mathrm{OH}$ ) to mound soil around the trunk base to cover and insulate the graft union (Fig. 2D, H, and L).
In early Spring 2016 and before budburst, all three training systems were converted back to the commercial standard VSP system. During conversion, vines were either cane- or spur-pruned, and two to four trunks/ vine were retained. Specifically, vines were trained using five training and pruning methods described as follows (Figs. 3 and 4): 1) F-2T2C [Fan in 2015 , converted in 2016 to the original training system used in the commercial vineyard; i.e., grapevines were head-trained with two trunks and cane-pruned with two canes tied horizontally to the fruit wire, consisting of 12 buds per cane, and totaling 24 buds per vine (Figs. 3A and 4A)], 2) F-4T4C [Fan in 2015, converted in 2016 to four trunks and four canes; this system was similar to 1 ), but each vine had four trunks and four canes and cane-pruned to a target of 32 buds per vine (Figs. 3B and 4B)], 3) $\mathrm{F} / \mathrm{VSP}-4 \mathrm{~T} 4 \mathrm{C}$ [Fan/VSP in 2015, converted in 2016 to four trunks and four canes; each vine had four trunks and four canes and cane-pruned to a target of 32 buds per vine (Figs. 3C and 4C)], 4) F/VSP-4T4CS [Fan/ VSP in 2015 , converted in 2016 to four trunks and four spur-pruned cordons; each vine had four trunks and four cordons that were pruned to two- to three-bud spurs, spaced evenly along the fruit wire, to a target of 32 buds per vine (Figs. 3D and 4D)], and 5) VSP-4T4CS [VSP in 2015 , maintained in 2016 with four trunks and four spur-pruned cordons: each vine had four trunks and four cordons pruned to two to three-bud spurs, spaced evenly along the fruit wire, to a target of 32 buds per vine (Figs. 3E and $4 \mathrm{E})]$. Clusters were thinned in all treatments after berry set (June 2016) according to shoot length as follows: all clusters were removed from shoots less than 12 inches long, one cluster per shoot was retained on shoots 12-24 inches long, and two clusters per shoot were retained on shoots greater than 24 inches long. Grapevines were maintained using vineyard practices similar to those used in 2015 . Pictures were taken to document growth progression of all training systems throughout the season (Fig. 4).

\section{Weather}

A temperature logger (Allo Watchdog A-Series; Spectrum Technologies, Aurora, IL) was installed in 


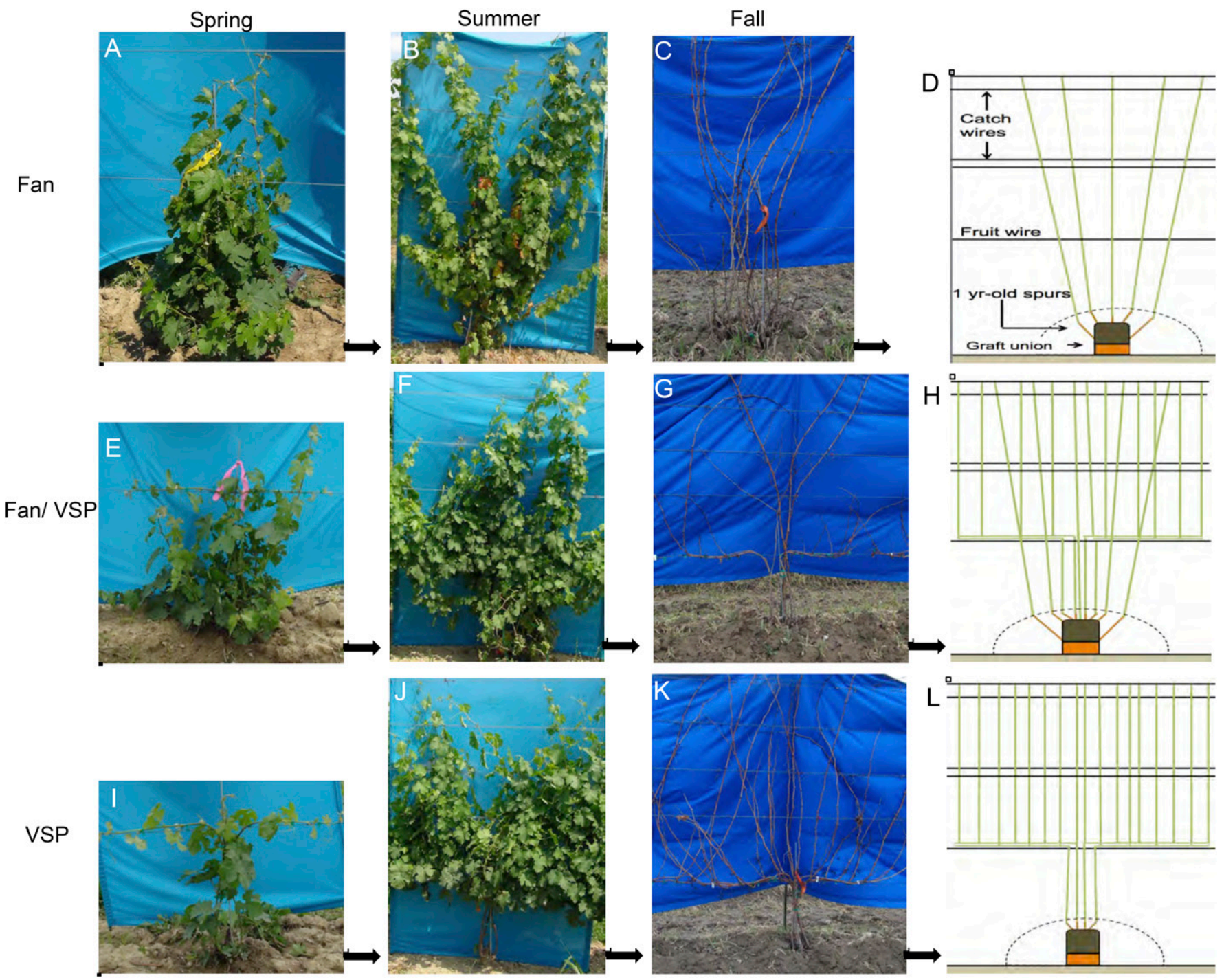

Fig. 2. Photos and schematic drawings of three training systems after vine dieback in 'Cabernet franc' grapevines during the 2015 growing season (Spring, Summer, and Fall): Fan training (A-D), Fan/vertical shoot positioning (VSP) training (E-H), and VSP training (I-L).

the vineyard $(<50 \mathrm{~m}$ away from vine plots) and positioned $4 \mathrm{ft}$ above the ground to record daily minimum and maximum temperatures throughout the duration of the study. Growing degree-days (GDDs) represent the cumulative heat units during the growing season and were calculated by adding the daily mean temperature above $10^{\circ} \mathrm{C}$ from 1 Apr. through 31 Oct. Fall frost date (first occurrence of temperature below $0{ }^{\circ} \mathrm{C}$ in the fall) and total number of frost-free days (FFDs) (number of successive days with a minimum daily temperature at or above $0{ }^{\circ} \mathrm{C}$ ) were also determined from the temperature logger data.

\section{Pruning and tying time}

In 2016, pruning and tying times of the five systems were recorded using a stopwatch. Timed activities of F-2T2C included cane selection for trunk replacement, bilateral training using training tape and ties, removal of excess canes, and pruning to 24 buds per vine (Figs. 3A and 4A). F4T4C involved similar activities except that 32 buds per vine were retained (Figs. 3B and 4B). Timed activities of F/VSP-4T4C included cane selection for trunk replacement, replacement of damaged or weak bilaterally trained cane(s) with fanned canes, removal of excess canes, and pruning to 32 buds per vine (Figs. 3C and 4C). F/VSP-4T4CS involved similar activities to the previous system except that 32 buds on canes and spurs were retained (Figs. 3D and 4D). Timed activities of VSP-4T4CS consisted of pruning vertical canes back to two- to three-bud spurs per vine for a total of 32 buds per vine (Figs. 3E and 4E).

\section{Vegetative growth}

BUD AND SHOOT COUNTS, AND LEAF AREA. In Spring 2016, bud and shoot number per vine were recorded. Leaf area was measured during veraison (initiation of fruit ripening) using a portable leaf area meter (LI-3000C; LI-COR Biosciences, Lincoln, NE). Leaf area per vine was estimated by multiplying the leaf number per vine by the mean single leaf area. The mean single leaf area was computed by scanning all mature leaves of six shoots per vine on two vines per experimental unit. We previously determined that this method provided a good estimate to predict the actual leaf area using 
\begin{tabular}{ll|l} 
(C) F/VSP-4T4C & (D) F/VSP-4T4CS & (E) VSP-4T4CS
\end{tabular}

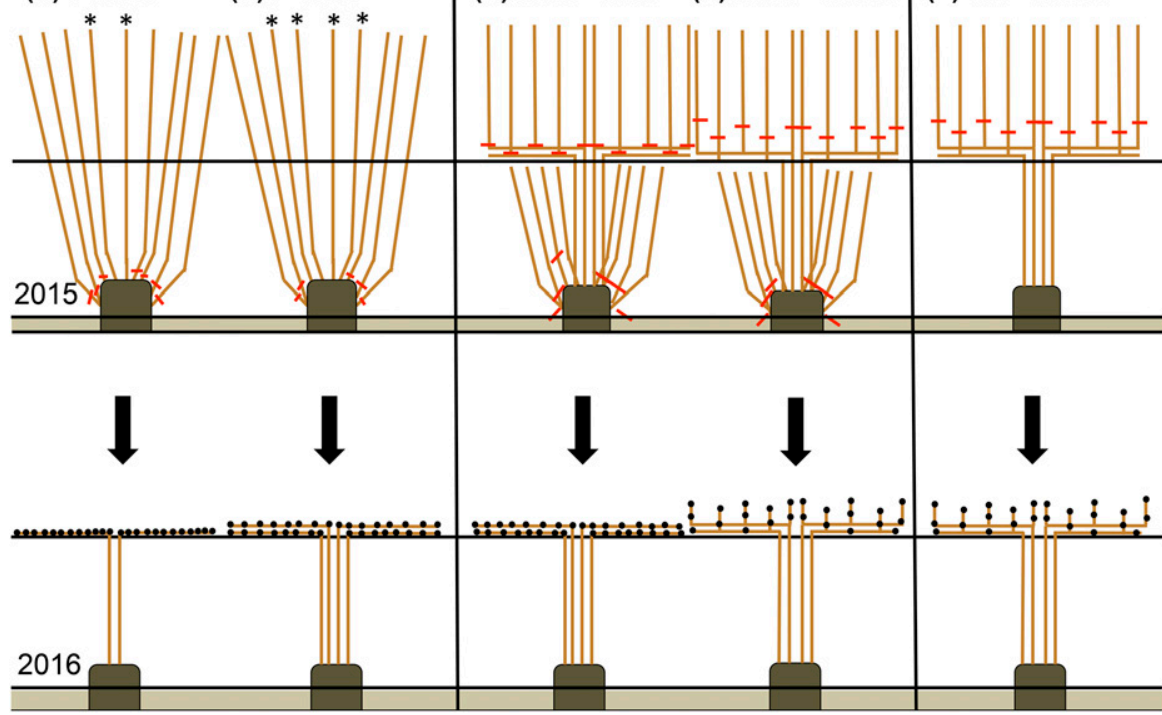

Fig. 3. Schematic drawings of the three grapevine training systems established in 2015 and converted to five systems in 2016. (A) F-2T2C: Fan-trained vine in 2015 converted to vertical shoot positioning (VSP) with two trunks and two canes, cane-pruned in 2016; (B) F-4T4C: Fan-trained vine in 2015 converted to VSP with four trunks and four canes, cane-pruned in 2016; (C) F/VSP-4T4C: Fan/VSP-trained vine in 2015 converted to VSP with four trunks and four canes, cane-pruned in 2016; (D) F/VSP-4T4CS: Fan/VSP-trained vine in 2015 converted to VSP with four trunks and four cordons, spur-pruned in 2016; and (E) VSP-4T4CS: VSP-trained vine in 2015 and maintained as VSP with four trunks and four cordons, spur-pruned in 2016.

linear regression $\left[R^{2}=0.90(\right.$ data not shown)].

TRUNK SIZE AND PRUNING WEIGHT. In Fall 2016, trunk diameter was measured with a caliper $(500$ Series; Mitutoyo Corp., Kawasaki, Japan) at internode 2 (stem tissue between node positions 2 and 3 ) of second-year trunks. In late Winter 2017, pruning weights of the 2016 growing season were recorded from five vines (experimental unit) using a digital scale (SD200L; Ohaus Corp., Parsippany, NJ). During pruning, all treatments were spur-pruned to twoto three-bud spurs, and 32 buds per vine were retained.

\section{Yield components}

At harvest, yield components including 100-berry weight, cluster number per vine, and crop weight per vine were recorded. Berry samples were collected from each experimental unit, placed in a sealed plastic bag, stored in a cooler with ice, and transported from Geneva to Wooster. The samples were stored at $4{ }^{\circ} \mathrm{C}$ overnight and processed

\section{Statistical analysis}

All data were subjected to oneway analysis of variance using SAS software (version 9.3; SAS Institute, Cary, NC). Fisher's least significant difference test at $P \leq 0.05$ was used to compare means. Regression analyses were computed to determine the relationship between leaf area and pruning weight, and the two cropload methods, LA/Y and RI.

\section{Results and discussion Weather}

Hourly maximum and minimum air temperatures from 1 Jan. 2015 to 31 Oct. 2016 are summarized in Fig. 1. In 2015, the lowest temperature $\left(-31.3{ }^{\circ} \mathrm{C}\right)$ was recorded on 20 Feb. As indicated earlier, all 1-yearold canes (aboveground vine parts) of 'Cabernet franc' grapevines were killed except those covered with soil. The last spring frost and the first fall frost occurred on 29 Apr. and 18 Oct. 2015 , respectively, resulting in a growing season of $170 \mathrm{FFD}$ and 1436 GDD. In 2016, the lowest temperature $\left(-20.1^{\circ} \mathrm{C}\right)$ was recorded on $18 \mathrm{Feb}$. and vines sustained minimal bud injury (4\%). The last spring frost and the first fall frost occurred on $15 \mathrm{Apr}$. and 23 Oct. 2016, respectively, resulting in a growing season of 189 FFD and 1605 GDD.

\section{Pruning and tying time}

Pruning time was the shortest in F-2T2C and F-4T4C, whereas F/ VSP-4T4C, F/VSP-4T4CS, and VSP4T4CS required longer pruning times (Fig. 5). However, tying time was the longest in $\mathrm{F}-2 \mathrm{~T} 2 \mathrm{C}$ and $\mathrm{F}-4 \mathrm{~T} 4 \mathrm{C}$ as compared with F/VSP-4T4C and F/ VSP-4T4CS, respectively. No tying was needed for VSP-4T4CS (Fig. 5). Total training (pruning and tying) time was the longest in F-4T4C and shortest in VSP-4T4CS (Fig. 5). During pruning, nearly $40 \%$ of vines in F/VSP-4T4C and F/VSP-4T4CS sustained dieback of the horizontally trained canes. Thus, these damaged canes were pruned and replaced with the fan-trained canes. This anomaly was observed only on vines trained on the combined system, F/VSP, the previous year (2015), and in other cultivars as well (Todaro, 2016). It is suggested that shading of the horizontally (VSP) and vertically (Fan) trained shoots/canes resulted from the combined training system (Fig. 


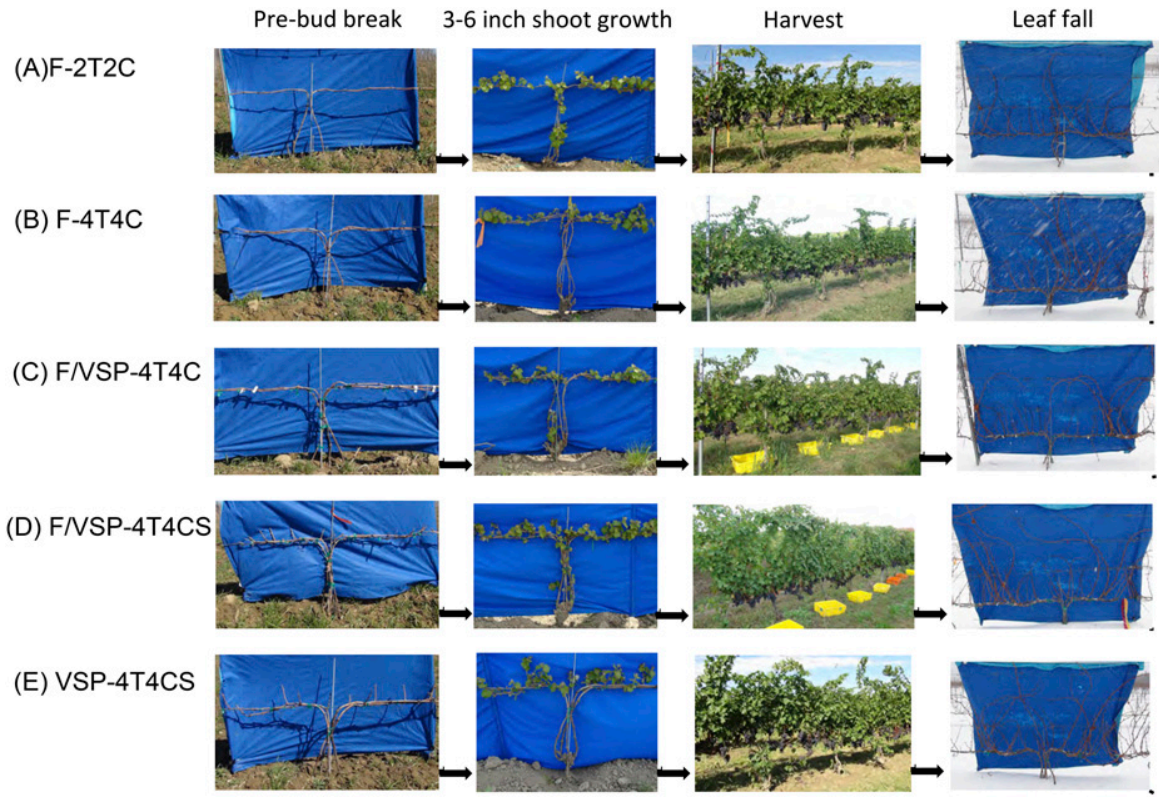

Fig. 4. Photos of the five training systems in 'Cabernet franc' grapevines during the 2016 growing season in April (pre-budbreak), May (3-6 inches shoot growth), October (harvest), and November (leaf fall): (A) F-2T2C $=2015$ Fan-trained vines converted in 2016 to head-trained with two trunks and cane-pruned with two canes, 12 buds per cane and totaling 24 buds per vine; (B) F-4T4C = 2015 Fan-trained vines converted in 2016 to four trunks and four canes pruned to a target of 32 buds per vine; (C) F/VSP-4T4C $=2015$ Fan- and vertical shoot positioning (VSP)-trained vines converted in 2016 to four trunks and four canes pruned to a target of 32 buds per vine; (D) F/VSP-4T4CS = 2015 Fan- and VSP-trained vines converted in 2016 to four trunks and four spur-pruned cordons that were pruned to two to three-bud spurs to a target of 32 buds per vine; and (E) VSP-4T4CS = VSP-trained vines in 2015 maintained in 2016 with four trunks and four spur-pruned cordons pruned to two- to three-bud spurs to a target of 32 buds per vine; 1 inch $=2.54 \mathrm{~cm}$.

$2 \mathrm{~F}$ and $2 \mathrm{H}$ ) and may have led to poor cold acclimation and thus cold injury of the shaded canes. This observation concurs with previous reports, which demonstrated that exposure of shoots and canes to sunlight during the growing season favored proper cold acclimation and resistance to cold during the dormant season (Howell, 2000; Howell and Shaulis, 1980).

\section{Vegetative growth}

Bud AND SHOOT COUNTS, AND LEAF AREA. VSP-trained vines (VSP4T4CS, F/VSP-4T4C, and F/VSP$4 \mathrm{~T} 4 \mathrm{CS})$ in the previous year (2015) had the highest number of buds per vine after pruning and the highest number of shoots per vine, whereas fan-trained vines (F-4T4C and F-2T2C) had the lowest number of buds after pruning and produced the lowest number of shoots (Table 1 ). This was expected because the former systems had increased number of buds and spurs retained after pruning and conversion. Nevertheless, shoot count per vine was unusually lower than bud count per vine in all training systems (Table 1). This discrepancy is explained by the presence of blind nodes (count buds remained closed with no shoot growth), which averaged four to five blind nodes per vine in all treatments. This suggested that the number of blind nodes were not related to the training method, but rather to bud damage possibly due to cold injury from the February and early spring subfreezing events.

VSP-4T4CS had the highest leaf area/vine followed by F-2T2C and $\mathrm{F}-4 \mathrm{~T} 4 \mathrm{C}$ which produced similar leaf area, whereas F/VSP-4T4C and F/VSP-4T4CS produced the lowest leaf area (Table 1). This unexpected decrease in leaf area in the latter two treatments is likely caused by shading of buds from the combined training system, F/VSP, during the previous season. It is suggested that shaded buds in 2015 produced leaves with reduced leaf area in 2016. We made the same observations in two other cultivars trained on F/VSP (Todaro, 2016). Previous work reported reduced leaf area per shoot 1 year after shading in vinifera grapevines (McArtney and Ferree, 1999).

Pruning Weight and trunk size. VSP-4T4CS and F-4T4C produced the highest, whereas F/VSP4T4C and F/VSP-4T4CS produced the lowest pruning weights per meter of canopy length (Table 1). In other words, pruning weight per vine followed a similar trend as leaf area per vine. Therefore, leaf area per vine at veraison provided a good prediction and explained $72 \%$ of the variation in pruning weight (Fig. 6). Our results confirm previous reports that leaf area is positively correlated with pruning weight (Bravdo et al., 1984; Kliewer and Antcliff, 1970). Furthermore, pruning weights ranged between 0.24 and $0.35 \mathrm{~kg} \cdot \mathrm{m}^{-1}$ among all treatments (Table 1). Based on previous reports, pruning weights of balanced vines should be within the ideal range of $0.3-0.6 \mathrm{~kg} \cdot \mathrm{m}^{-1}$ (Smart and Robinson, 1991). In this study, only VSP4T4CS and F-4T4C vines had pruning weights within the ideal range and hence were considered to have optimum size.

VSP-4T4CS produced the largest second-year trunks, whereas grapevines that were previously trained on a Fan system (F-2T2C and F-4T4C) produced the smallest trunks (Table 1). The combined F/VSP system produced trunk diameter of moderate size (Table 1). The large diameter of newly retrained trunks is indicative of excessive vigor and thus is not desirable because it might lead to increased cold injury (Byrne and Howell, 1978; Howell and Shaulis, 1980). In fact, we have recently demonstrated that bud and vascular tissue from vigorous (also called "bull") canes were more cold sensitive than normal-sized canes in 'Cabernet franc' grapevines (Todaro and Dami, 2017). Following trunk injury and to restore growth balance, grapevines are managed differently by training multiple shoots from the trunk base on a Fan training system (Wolfe, 2000; Zabadal et al., 2007). This is why the vines trained with multiple shoots ( $>4$ shoots) on a Fan system in 2015 produced normal-sized trunks in 
2016, whereas vines trained on VSP with two or four shoots only in 2015 produced large (vigorous) trunks in 2016. Based on our previous work on trunk size and its subsequent impact on cold injury, we concluded that Fantrained systems, F-2T2C and F-4T4C, were the most desirable.

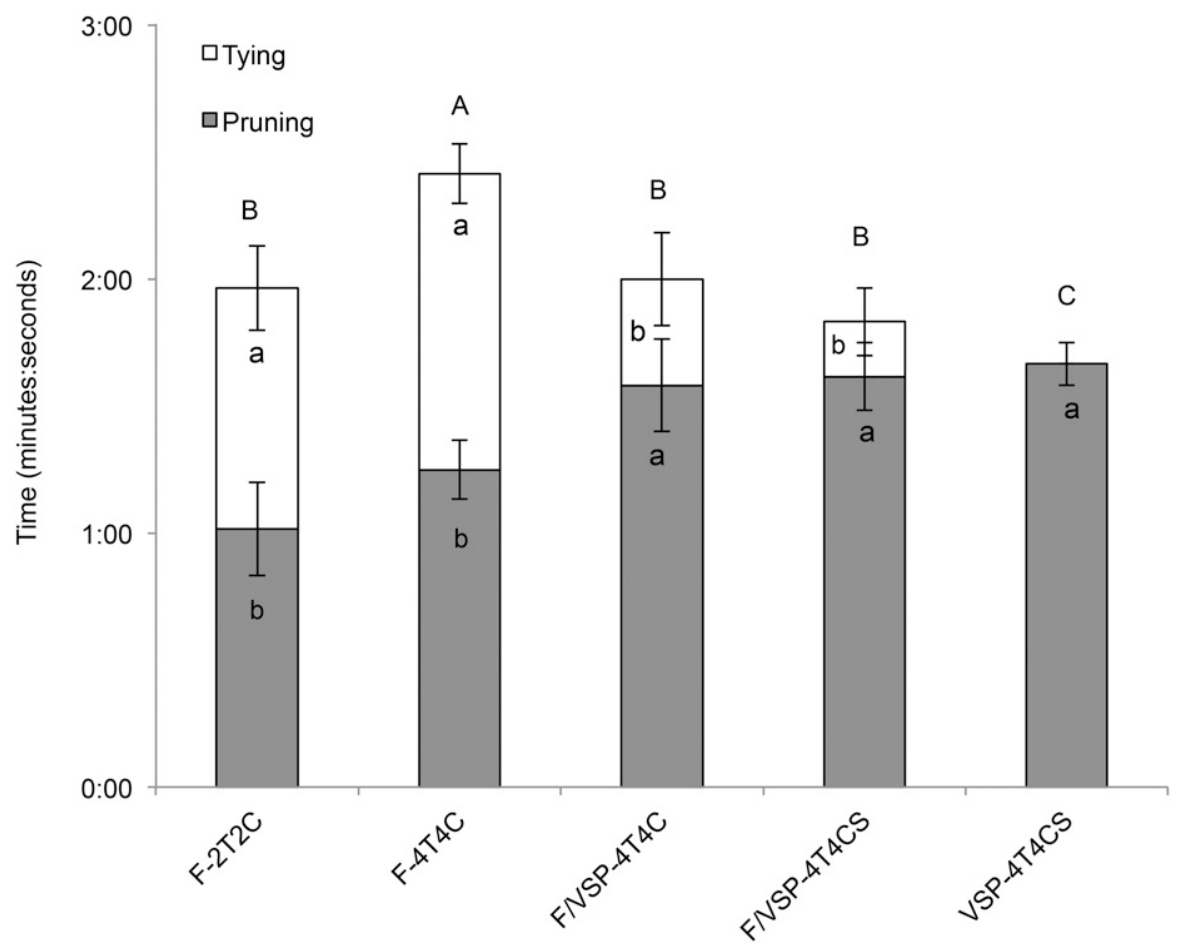

Fig. 5. Pruning and tying time of 'Cabernet franc' grapevines trained on five systems at Geneva, $\mathrm{OH}$, in Spring 2016: F-2T2C = 2015 Fan-trained vines converted in 2016 to head-trained with two trunks and cane-pruned with two canes, 12 buds per cane and totaling 24 buds per vine; F-4T4C $=2015$ Fan-trained vines converted in 2016 to four trunks and four canes pruned to a target of 32 buds per vine; F/VSP-4T4C = 2015 Fan- and vertical shoot positioning (VSP)-trained vines converted in 2016 to four trunks and four canes pruned to a target of 32 buds per vine; F/VSP-4T4CS = 2015 Fan- and VSP-trained vines converted in 2016 to four trunks and four spur-pruned cordons that were pruned to two- to three-bud spurs to a target of 32 buds per vine; VSP-4T4CS = VSP-trained vines in 2015 maintained in 2016 with four trunks and four spur-pruned cordons pruned to two- to three-bud spurs to a target of 32 buds per vine. Means with different letters are significantly different by Fisher's least significant difference test at $P \leq \mathbf{0 . 0 5}$. Lower case letters in grey plot area correspond to means separation of pruning time. Lower case letters in white plot area correspond to means separation of tying time. Upper case letters above the white plot area correspond to means separation of total training (pruning and tying) time.

\section{Yield components and fruit composition}

VSP-4T4CS produced the highest, whereas F-2T2C produced the lowest cluster number and yield per vine, which was expected considering F-2T2C and VSP-4T4CS had the lowest and highest number of buds per vine after pruning, respectively (Tables 1 and 2). However, VSP4T4CS produced fruit with the lowest TSS, whereas F-2T2C had the highest TSS (Table 2). In other words, the training systems with the largest yields had the lowest TSS and vice versa. Juice $\mathrm{pH}$ and titratable acidity were not different among treatments. Similar responses have been previously reported and are typical of increased crop levels resulting in delayed fruit ripening (Dami et al., 2006; Naor et al., 2002). Under the climatic conditions of northeast Ohio, delaying harvest to ripen the fruit may not be desirable because of the short growing season and the risk of a fall killing frost occurrence before complete fruit maturity.

CROPLOAD. The LA/Y's of F-2T2C and F-4T4C were the highest, whereas those of F/VSP-4T4C, F/VSP-4T4CS, and VSP-4T4CS were the lowest (Table 2). Previous research found that $0.8-1.2 \mathrm{~m}^{2}$ leaf area per kilogram of fruit were considered ideal ratios for single canopy-trained vines (Kliewer and Dokoozlian, 2005). Therefore, F-2T2C was the only system that fell outside the ideal range and those vines were considered to be under-cropped. When cropload was expressed as yield per pruning weight ratio, RI values ranged between 7 and 13 (Table 2). Cropload or the ratio between crop yield and dormant vine pruning weight is

Table 1. Bud and shoot counts, leaf area, pruning weight, and trunk diameter of 'Cabernet franc' grapevines grown on different training systems at a commercial vineyard at Geneva, $\mathrm{OH}$, in 2016.

\begin{tabular}{|c|c|c|c|c|c|}
\hline Treatment $^{\mathrm{z}}$ & Nodes (no./vine) & Shoots (no./vine) & Leaf area $\left(\mathrm{m}^{2} / \text { vine }\right)^{\mathrm{y}}$ & Pruning wt $\left(\mathrm{kg} \cdot \mathrm{m}^{-1}\right)^{\mathrm{y}}$ & Trunk diam $(\mathrm{mm})^{\mathrm{y}}$ \\
\hline 1) $\mathrm{F}-2 \mathrm{~T} 2 \mathrm{C}$ & $23 \mathrm{~d}^{\mathrm{x}}$ & $19 \mathrm{~d}$ & $3.35 \mathrm{~b}$ & $0.26 \mathrm{bc}$ & $13 \mathrm{c}$ \\
\hline 2) F-4T4C & $28 \mathrm{c}$ & $23 c$ & $3.66 \mathrm{~b}$ & $0.31 \mathrm{ab}$ & $13 \mathrm{c}$ \\
\hline 3) F/VSP-4T4C & $32 \mathrm{~b}$ & $28 \mathrm{~b}$ & $2.57 \mathrm{c}$ & $0.24 \mathrm{c}$ & $14 \mathrm{bc}$ \\
\hline 4) F/VSP-4T4CS & $35 \mathrm{ab}$ & $31 \mathrm{ab}$ & $2.37 \mathrm{c}$ & $0.24 \mathrm{c}$ & $14.5 \mathrm{~b}$ \\
\hline 5) VSP-4T4CS & $37 \mathrm{a}$ & $33 \mathrm{a}$ & $4.42 \mathrm{a}$ & $0.35 \mathrm{a}$ & $18.5 \mathrm{a}$ \\
\hline$P$ value & $<0.0001$ & $<0.0001$ & 0.0292 & 0.0133 & $<0.0001$ \\
\hline
\end{tabular}

$\left.{ }^{\mathrm{z}} \mathrm{l}\right) \mathrm{F}-2 \mathrm{~T} 2 \mathrm{C}=2015$ Fan-trained vines converted in 2016 to head-trained with two trunks and cane-pruned with two canes, 12 buds per cane and totaling 24 buds per vine; 2 ) F$4 \mathrm{~T} 4 \mathrm{C}=2015$ Fan-trained vines converted in 2016 to four trunks and four canes pruned to a target of 32 buds per vine; 3 ) F/VSP-4T4C $=2015$ Fan- and vertical shoot positioning (VSP)-trained vines converted in 2016 to four trunks and four canes pruned to a target of 32 buds per vine; 4 ) F/VSP-4T4CS = 2015 Fan- and VSP-trained vines converted in 2016 to four trunks and four spur-pruned cordons that were pruned to two- to three-bud spurs to a target of 32 buds per vine; 5 ) VSP-4T4CS = VSP-trained vines in 2015 maintained in 2016 with four trunks and four spur-pruned cordons pruned to two- to three-bud spurs to a target of 32 buds per vine.

${ }^{\mathrm{y}} 1 \mathrm{~m}^{2}=10.7639 \mathrm{ft}^{2}, \mathrm{l} \mathrm{kg} \cdot \mathrm{m}^{-1}=0.6720 \mathrm{lb} / \mathrm{ft}$, and $1 \mathrm{~mm}=0.0394$ inch.

${ }^{\mathrm{x}}$ Means followed by different letters in columns are significantly different by Fisher's least significant difference test at $P \leq 0.05$. 

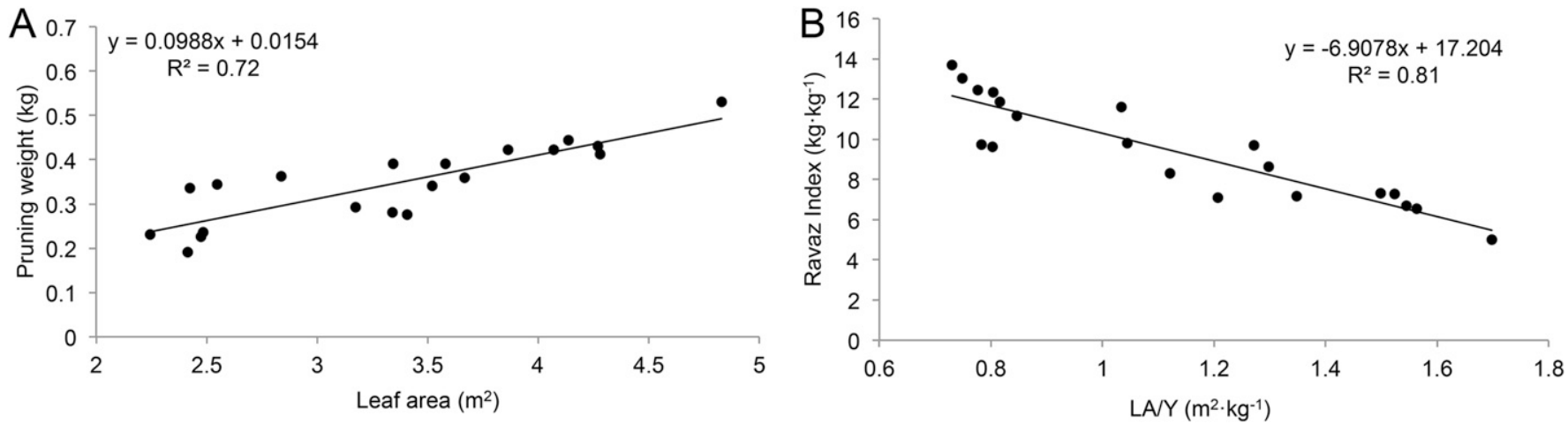

Fig. 6. Linear regressions of two vegetative growth parameters and two cropload parameters in grapevines. (A) Linear regression between leaf area and pruning weight of the 2016 growth. (B) Linear regression between leaf area to yield ratio $(\mathrm{LA} / \mathrm{Y})$ and Ravaz index (yield: pruning weight ratio) of the 2016 growth; $1 \mathrm{~m}^{2}=10.7639 \mathrm{ft}^{2}, 1 \mathrm{~kg}=2.2046 \mathrm{lb}$, and $1 \mathrm{~m}^{2} \cdot \mathrm{kg}^{-1}=4.8824 \mathrm{ft}^{2} / \mathrm{lb}$.

Table 2. Yield components and fruit composition of 'Cabernet franc' grapevines grown on different training systems at a commercial vineyard at Geneva, $\mathrm{OH}$, in 2016.

\begin{tabular}{|c|c|c|c|c|c|c|c|}
\hline \multirow[b]{2}{*}{ Treatment $^{\mathrm{z}}$} & \multicolumn{3}{|c|}{ Yield components } & \multicolumn{4}{|c|}{ Fruit composition } \\
\hline & Clusters (no./vine) & $\begin{array}{c}\text { Yield } \\
{\text { (kg/vine })^{y}}^{-}\end{array}$ & $\begin{array}{l}\text { Leaf area:yield } \\
\left(\mathrm{m}^{2} \cdot \mathrm{kg}^{-1}\right)^{\mathrm{y}}\end{array}$ & Ravaz index ${ }^{x}$ & TSS $(\%)^{\mathrm{w}}$ & $\mathrm{pH}$ & $\mathrm{TA}\left(\mathrm{g} \cdot \mathrm{L}^{-1}\right)^{\mathrm{v}}$ \\
\hline 2) F-4T4C & $30 \mathrm{~b}$ & $2.8 \mathrm{~b}$ & $1.27 \mathrm{ab}$ & $9 \mathrm{bc}$ & $19.8 \mathrm{ab}$ & $3.35 \mathrm{a}$ & $5.33 \mathrm{a}$ \\
\hline 3) F/VSP-4T4C & $28 \mathrm{~b}$ & $2.5 \mathrm{~b}$ & $1.09 \mathrm{~b}$ & $10 \mathrm{abc}$ & $20.1 \mathrm{ab}$ & $3.33 \mathrm{a}$ & $5.03 \mathrm{a}$ \\
\hline 4) $\mathrm{F} / \mathrm{VSP}-4 \mathrm{~T} 4 \mathrm{CS}$ & $33 \mathrm{~b}$ & $3.1 \mathrm{~b}$ & $0.77 \mathrm{c}$ & $13 \mathrm{a}$ & $19.3 \mathrm{~b}$ & $3.36 \mathrm{a}$ & $5.03 \mathrm{a}$ \\
\hline
\end{tabular}

$\left.{ }^{\mathrm{z}} 1\right) \mathrm{F}-2 \mathrm{~T} 2 \mathrm{C}=2015$ Fan-trained vines converted in 2016 to head-trained with two trunks and cane-pruned with two canes, 12 buds per cane and totaling 24 buds per vine; 2 ) F$4 \mathrm{~T} 4 \mathrm{C}=2015 \mathrm{Fan}$-trained vines converted in 2016 to four trunks and four canes pruned to a target of 32 buds per vine; 3) F/VSP-4T4C $=2015$ Fan- and vertical shoot positioning (VSP)-trained vines converted in 2016 to four trunks and four canes pruned to a target of 32 buds per vine; 4) F/VSP-4T4CS = 2015 Fan- and VSP-trained vines converted in 2016 to four trunks and four spur-pruned cordons that were pruned to two- to three-bud spurs to a target of 32 buds per vine; 5) VSP-4T4CS = VSP-trained vines in 2015 maintained in 2016 with four trunks and four spur-pruned cordons pruned to two- to three-bud spurs to a target of 32 buds per vine.

${ }^{y} 1 \mathrm{~kg}=2.2046 \mathrm{lb}$ and $\mathrm{l} \mathrm{m}^{2} \cdot \mathrm{kg}^{-1}=4.8824 \mathrm{ft}^{2} / \mathrm{lb}$

${ }^{x}$ Ratio of yield to pruning weight per vine.

${ }^{\mathrm{w}}$ TSS $=$ total soluble solids dissolved within the juice.

${ }^{\mathrm{v}} \mathrm{TA}=$ titratable acidity measured as grams of tartaric acid per liter of juice; $1 \mathrm{~g} \cdot \mathrm{L}^{-1}=1000 \mathrm{ppm}$

"Means followed by different letters in columns are significantly different by Fisher's least significant difference test at $P \leq 0.05$.

a criterion of vine balance (Smart and Robinson, 1991). Generally, vines with cropload values between 4 and 10 are considered in the optimal range (Kliewer and Dokoozlian, 2005; Smart and Robinson, 1991). Based on that information, most training systems were within the ideal range except in F/VSP-4T4CS and VSP-4T4CS, which trended toward over-cropping. Furthermore, because cropload is an indicator of the source-sink relationship between the vegetative and reproductive growth, both methods delivered similar results and the LA/Y was a good predictor explaining $81 \%$ of the variation in RI (Fig. 6). Therefore, our results agree with previous reports that both ratios adequately represent the cropload status (Bravdo et al., 1984; Kliewer and Dokoozlian, 2005; Smart and Robinson, 1991).
In summary, this study has provided research-based information on the advantages and disadvantages among the five training and pruning methods (Table 3). Even though some systems may be less costly to train and prune, and/or may produce a larger crop than others, the overriding decision should be made based on producing balanced grapevines with optimum trunk size to mitigate future cold damage. Under those premises and among the five tested, the optimum training-pruning method was the Fan training pruned to four trunks and four canes, or F-4T4C, because it produced optimum trunk size, yield, cropload, and mature fruit (Table 3). Therefore, following trunk freeze injury, we recommend retaining all shoots using the Fan training during the growing season. During the subsequent dormant season, growers should select medium-sized canes for trunk replacement and train four trunks and four canes for the VSP system.

\section{Literature cited}

Bravdo, B., Y. Hepner, C. Loinger, S. Cohen, and H. Tabacman. 1984. Effect of crop level on growth, yield and wine quality of a high yielding Carignan vineyard. Amer. J. Enol. Viticult. 35:247-252.

Byrne, M.E. and G.S. Howell. 1978. Initial response of Baco noir grapevines to pruning severity, sucker removal, and weed control. Amer. J. Enol. Viticult. 29:192-198.

Dami, I.E., B. Bordelon, D. Ferree, M. Brown, M. Ellis, R. Williams, and D. Doohan. 2005. Midwest grape production guide. Ohio State Univ. Ext. Bul. 919. 


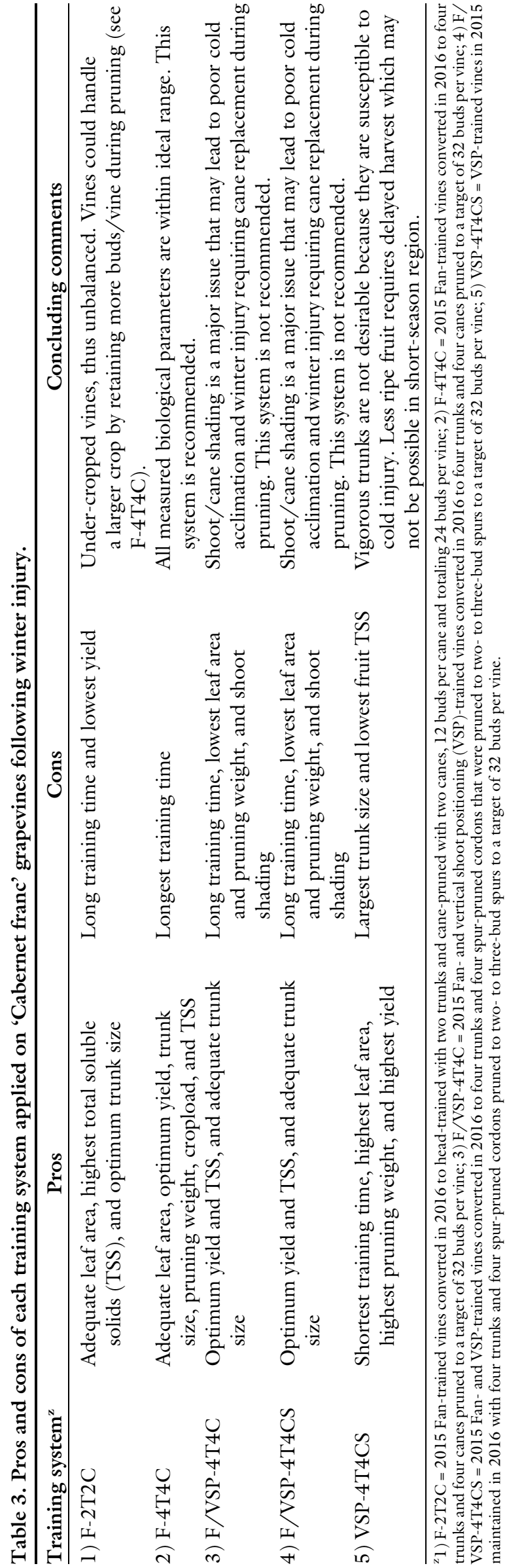

Dami, I.E., D. Ferree, A. Prajitna, and D. Scurlock. 2006. A five-year study on the effect of cluster thinning on yield and fruit composition of 'Chambourcin' grapevines. HortScience 41:586-588.

Dami, I.E., D. Kinney, and S. Li. 2014. Polar vortex and its impact on grapes. Ohio Grape-Wine Electronic Nwsl. 10 Jan. 2014 issue, p. 2-6. 26 Mar. 2018. <https://ohiograpeweb.cfaes.ohio-state. edu/pdf-newsletter/newslettertge $>$.

Dami, I.E. and D. Lewis. 2014. 2014 Grape winter damage survey report. Ohio State Univ., Dept. Hort. Crop Sci., Wooster, HCS Series 816. 26 Mar. 2018. <https://ohiograpeweb.cfaes.ohio-state. edu/sites/grapeweb/files/imce/pdf factsheets $/ 2014 \% 20$ Winter $\% 20 \mathrm{Grape} \%$ 20Damage\%20Survey_Results_Final\% 20 Report__Dami_March\%202014\% $281 \% 29$.pdf $>$.

Howell, G.S. 1988. Cultural manipulation of vine cold hardiness. Proc. Second Intl. Cool Climate Viticult. Oenology Symp., Auckland, New Zealand, p. 98-102.

Howell, G.S. 2000. Grapevine cold hardiness: Mechanisms of cold acclimation, mid-winter hardiness maintenance, and spring acclimation. Amer. J. Enol. Viticult. 51:35-48.

Howell, G.S. and N.J. Shaulis. 1980. Factors influencing within-vine variation in the cold resistance of cane and primary bud tissues. Amer. J. Enol. Viticult. 31:158-161.

Kliewer, W.M. and A.J. Antcliff. 1970. Influence of defoliation, leaf darkening and cluster shading on the growth and composition of Sultana grapes. Amer. J. Enol. Viticult. 21:26-36.

Kliewer, M.W. and N.K. Dokoozlian. 2005. Leaf area/crop weight ratios of grapevines: Influence on fruit composition and wine quality. Amer. J. Enol. Viticult. 56:170-181.

McArtney, S.J. and D.C. Ferree. 1999. Shading effects on dry matter partitioning, remobilization of stored reserves and early season vegetative development of grapevines in the year after treatment. J. Amer. Soc. Hort. Sci. 124:591-597.

Naor, A., Y. Gal, and B. Bravdo. 2002. Shoot and cluster thinning influence vegetative growth, fruit yield, and wine quality of 'Sauvignon blanc' grapevines. J. Amer. Soc. Hort. Sci. 127:628-634.

Poling, E.B. 2008. Spring cold injury to wine grapes and protection strategies and methods. HortScience 43:1652-1662.

Pool, R.M. and G.E. Howard. 1985. Managing vineyards to survive low temperatures with some potential varieties for 


\section{Preliminary and Regional Reports}

hardiness. Proc. Intl. Symp. Cool Climate Viticult. Enol., Corvallis, OR, p. 184197.

Smart, R. and M. Robinson. 1991. Sunlight into wine: A handbook for winegrape canopy management. Winetitles, Ashford, Austrialia.

Todaro, T.M. 2016. Evaluating cultural practices for recovery from cold damage in grapevines. Ohio State Univ., Columbus, MS Thesis.
Todaro, T.M. and I.E. Dami. 2017. Cane morphology and anatomy influence freezing tolerance in Vitis vinifera Cabernet franc. Intl. J. Fruit Sci. 17:391406.

U.S. Department of Agriculture. 2012 USDA plant hardiness zone map. 1 Jan. 2018. <http://planthardiness.ars.usda. gov>.

Wolfe, W. 2000. Vine and vineyard management following low temperature injury. Proc. Amer. Soc. Enol. Viticult. 50th Anniversary Ann. Mtg., Davis, CA, p. 101-110.

Zabadal, T.J., I.E. Dami, M.C. Goffinet, T.E. Martinson, and M.L. Chien. 2007. Winter injury to grapevines and methods of protection. Michigan State Univ. Ext. Bul. 2930. 